\title{
Rapid-scan operando infrared spectroscopy
}

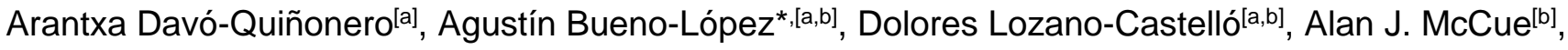 \\ James A. Anderson ${ }^{[b]}$
}

\begin{abstract}
A novel methodology, referred to as rapid-scan operando, has been demonstrated to be a highly powerful tool for the study of reaction mechanisms in heterogeneous catalysis, because it combines rapid-scan for IR monitoring in the milliseconds time frame and operando methodology. As a proof of concept, the NOx-CO and $\mathrm{NOx}-\mathrm{H}_{2}$ reactions have been studied as model catalyzed reactions with practical interest for the removal of NOx in Diesel exhausts. Rapid-scan operando experiments have confirmed the state-of-theart knowledge concerning the reaction mechanisms, and more importantly, have allowed us to elucidate, for the first time, the different role of surface hydroxyls groups depending on the reductant used $\left(\mathrm{CO}\right.$ or $\left.\mathrm{H}_{2}\right)$. Moreover, this new tool has been used to distinguish the behavior of carbonates and nitrites under reaction conditions, which cannot be monitored by conventional IR approaches due to overlap of their absorbance bands.
\end{abstract}

Infrared spectroscopy (IR) is a powerful tool to investigate reaction mechanisms, being of special relevance for the study of reactions accelerated by solid catalysts. This technique is able to provide valuable information about the species formed and depleted on the catalyst surface.

In early spectroscopic studies performed at the end of the $19^{\text {th }}$ century, obtaining a spectrum was a tedious job requiring 3-4 hours or more, since each point in the spectrum had to be measured separately. ${ }^{[1]}$ After World War II advances in electronics made it possible to obtain a spectrum in 1-2 hours, ${ }^{[1]}$ and this time was dramatically reduced to a few seconds in the $1970^{\text {s }}$ with the utilization of the fast Fourier transform algorithm ${ }^{[2]}$ and appropriate microcomputing.

Important advances were made in the study of reaction mechanisms by IR spectroscopy in the $1980^{\text {s }}$ with the development of in situ cells, where the sample to be analyzed is treated in a controlled thermal and chemical environment and the IR analysis is performed without contact with the ambient atmosphere. Further progress was achieved at the beginning of the $21^{\text {st }}$ century with the design of operando systems, which combine spectroscopic monitoring with reaction rates measurements, by special attention given to the design of the reaction cells to ensure that the reaction takes place under kinetic control. In this article, it is demonstrated that these modern setups can be further improved and a new concept is introduced, which is referred to as rapid-scan operando. This new rapid-scan operando methodology is of special relevance for the study of heterogeneous catalysis. Other advances have been recently made in the available infrared techniques to improve the study of heterogeneously catalyzed reactions. For instance, Urakawa et al. ${ }^{[3]}$ combined DRIFTS analysis with Raman spectroscopy to obtain information about the catalyst surface and bulk.

The Rapid-scan methodology presented in this article consists of IR monitoring within fraction of seconds time frame, which can be achieved using high resolution modern spectrometers because few scans, or even only one, provide suitable signal to noise ratio and sufficient definition in the spectra. In the examples shown here, rapid-scan operando experiments were performed by recording one scan every 140 milliseconds. The reactions selected as proof-of-concept are the reduction of NOx with $\mathrm{CO}$ and $\mathrm{H}_{2}$, which have practical interest for the removal of NOx in Diesel exhausts. ${ }^{[4]}$ Operando DRIFTS-MS has demonstrated to be a powerful tool to study these reactions, ${ }^{[5]}$ and here is shown that further insights can be achieved when the spectrometer is operated in rapid-scan mode.

Two model NOx Storage and Reduction (NSR) catalysts have been used, which are referred to as $\mathrm{CuO} / \mathrm{CeO}_{2}$ and $\mathrm{CuO} / \mathrm{Ce}_{0.8} \mathrm{Zr}_{0.2} \mathrm{O}_{2}$. These catalysts continuously chemisorb NOx and are periodically regenerated by feeding pulses of a reductant following the NSR technology developed by Toyota. ${ }^{[6]}$ Figure 1 shows two DRIFT spectra recorded under reaction conditions with the $\mathrm{CuO} / \mathrm{Ce}_{0.8} \mathrm{Zr}_{0.2} \mathrm{O}_{2}$ catalyst in a conventional manner, that is, each spectrum was obtained by averaging scans over a period of 75 seconds. The temperature of the samples was $400^{\circ} \mathrm{C}^{[7]}$ The nature of the species identified in both spectra are similar, regardless the nature of the reductant used $\left(\mathrm{CO}\right.$ or $\left.\mathrm{H}_{2}\right)$. The bands at 1550 and $1240 \mathrm{~cm}^{-1}$, are consistent with the presence of nitrates on the catalyst, ${ }^{[8]}$ and the band at $3615 \mathrm{~cm}^{-1}$ can be attributed to hydroxyl groups. The shoulders at $1438 \mathrm{~cm}^{-1}$ could be assigned either to nitrites or to carbonates ${ }^{[9]}$ and the narrow peak at $2350 \mathrm{~cm}^{-1}$, which is only observed during $\mathrm{CO}$ pulses, is due to the presence of gas phase $\mathrm{CO}_{2}$ as a $\mathrm{CO}$ oxidation product.

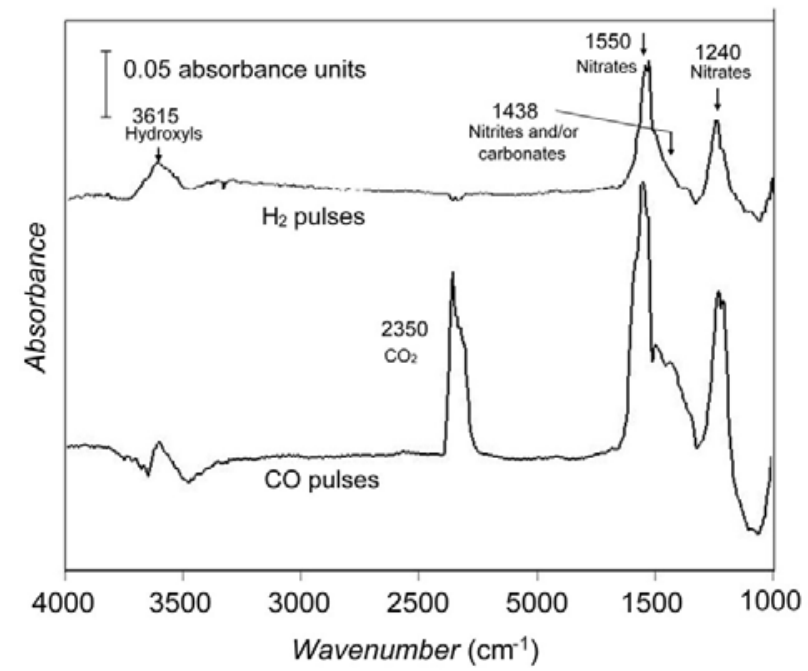

Figure 1. DRIFT spectra of $\mathrm{CuO} / \mathrm{Ce}_{0.8} \mathrm{Zr}_{0.2} \mathrm{O}_{2}$ recorded at $400^{\circ} \mathrm{C}$ in a $50 \mathrm{ml} / \mathrm{min}$ flow of $850 \mathrm{ppm} \mathrm{NOx}+5 \% \mathrm{O}_{2}+\mathrm{N}_{2}$ (balance) and $100 \mu \mathrm{L}$ pulses of $\mathrm{H}_{2}$ or $\mathrm{CO}$ every 30 seconds. A background spectrum recorded at $400^{\circ} \mathrm{C}$ in $\mathrm{He}$ flow has been subtracted.

The conclusions regarding the possible reaction mechanism as deduced from these spectra on Figure 1 are consistent with the generally accepted NSR reactions pathway. ${ }^{[10]}$ NOX is chemisorbed on the catalyst mainly in the form of nitrates, which implies that nitrogen on NO (which is the main nitrogen oxide in the feed) is oxidized from $2+$ to $5+$. The NOx removal curves (included in Figure 2) confirm the net removal of NOx from the gas stream, and therefore, confirm that $\mathrm{CO}$ and $\mathrm{H}_{2}$ reduce part of 
the chemisorbed NOx species closing the NOx storage-reduction cycle.

However, there are several questions that cannot be answered on the basis of the spectra in Figure 1, such as the role of the hydroxyl groups or provide a less ambiguous assignment of the band at $1438 \mathrm{~cm}^{-1}$. A deeper analysis of the reaction mechanism can be provided by rapid-scan monitoring.

Figure 2 shows the absorbance at selected wavenumbers as a function of time and the NOx removed in the operando experiments performed with the catalysts $\mathrm{CuO} / \mathrm{Ce}_{0.8} \mathrm{Zr}_{0.2} \mathrm{O}_{2}$ (Figure 2a) and $\mathrm{CuO} / \mathrm{CeO}_{2}$ (Figure 2b). The general behavior of both catalysts is qualitatively similar. Initially, both catalysts remove NOx from the gas stream and the nitrates signal (band at $1550 \mathrm{~cm}^{-1}$ ) increases with time. The $\mathrm{CuO} / \mathrm{CeO}_{2}$ catalyst (Figure $2 \mathrm{~b}$ ) only form nitrates while $\mathrm{CuO} / \mathrm{Ce}_{0.8} \mathrm{Zr}_{0.2} \mathrm{O}_{2}$ additionally shows changes in the band at $1438 \mathrm{~cm}^{-1}$ (Figure 2a) due to nitrites and/or to carbonates. $\mathrm{CO}$ is unable to completely regenerate the catalyst during each pulse, and the NOx removal capacity of the catalysts decreases with time upon $\mathrm{CO}$ pulses. On the other hand, $\mathrm{H}_{2}$ is much more effective than $\mathrm{CO}$, as previously reported, ${ }^{[11]}$ and $\mathrm{NOx}$ removal increases progressively during $\mathrm{H}_{2}$ pulses and the population of nitrates stored on the catalysts decreases concordantly. The better regeneration achieved by $\mathrm{H}_{2}$ has been attributed to its higher reactivity. ${ }^{[12]}$

The cyclic behavior of the NSR process is clear in most profiles in Figure 2, and this is an advantage of the rapid-scan methodology with regard to conventional operando experiments, because changes occurring in the milliseconds time frame can be studied. This is useful, for instance, to investigate the role of hydroxyl groups (3605-3615 cm-1) which exhibit a quite particular behavior. Conventional spectra (Figure 1) show that the hydroxyls band is quite similar during $\mathrm{CO}$ and $\mathrm{H}_{2}$ pulses. However, rapid-scan monitoring shows notable differences in the absorbance of hydroxyls over a shorter time frame. The absorbance of hydroxyls remains constant during pulses of $\mathrm{CO}$, suggesting that hydroxyls are not participating in the reaction, but act as spectators, and this feature is similar for both catalysts. Hydroxyls were formed during the first minute under the $\mathrm{NOx}+\mathrm{O}_{2}+\mathrm{N}_{2}$ mixture, and it is postulated that the chemisorption of NOx leads to the decomposition of bicarbonates (and carbonates) initially present on the catalyst, emitting $\mathrm{CO}_{2}$ and leaving hydroxyls on the surface. However, as mentioned, these hydroxyls do not participate further in the NSR reaction performed with CO as reductant. However, the absorbance of hydroxyls follows the shape of pulses during $\mathrm{H}_{2}$ injections, and this means that hydroxyls in this case are created and depleted. This means that the role of hydroxyls is quite different during $\mathrm{CO}$ and $\mathrm{H}_{2}$ pulses.

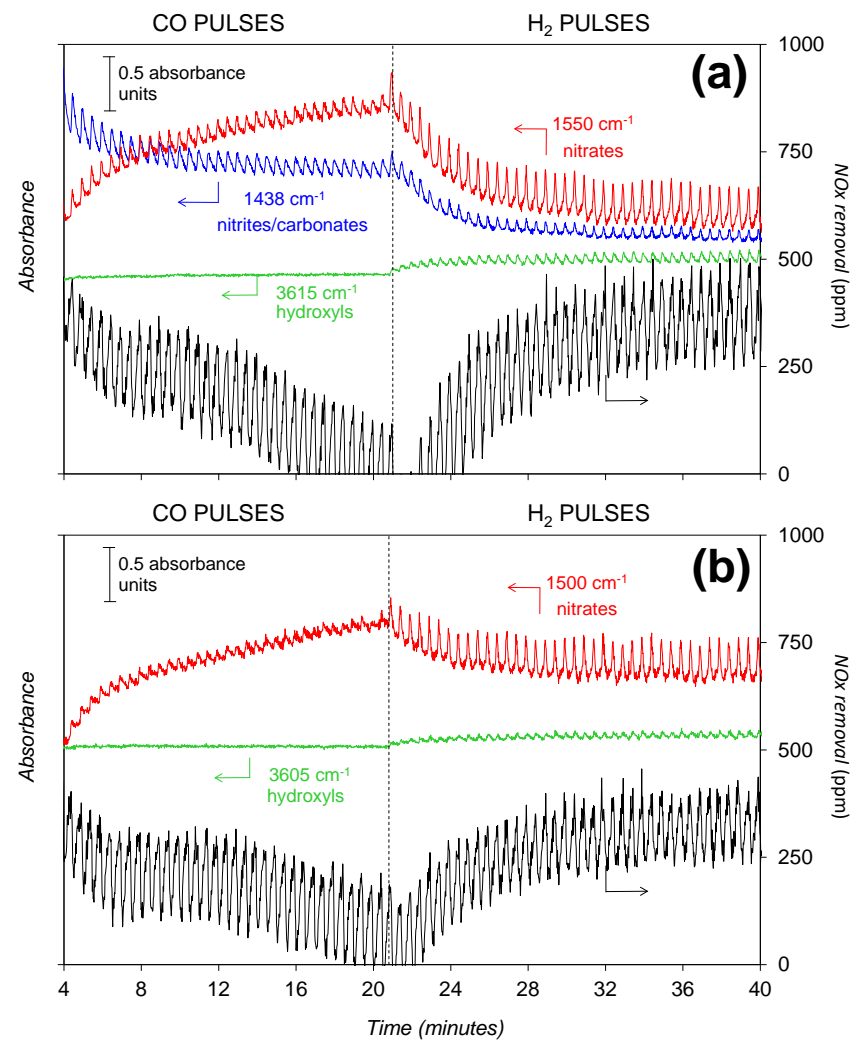

Figure 2. Absorbance at selected wavenumbers monitored by rapid-scan DRIFTS and NOx removed in experiments performed with (a) CuO/Ce $\mathrm{C}_{0.8} \mathrm{Zr}_{0.2} \mathrm{O}_{2}$ and (b) $\mathrm{CuO} / \mathrm{CeO}_{2}$ in a $50 \mathrm{ml} / \mathrm{min}$ flow of $850 \mathrm{ppm} \mathrm{NO}+5 \% \mathrm{O}_{2}+\mathrm{N}_{2}$ (balance) and $100 \mu \mathrm{L}$ pulses of $\mathrm{CO}$ or $\mathrm{H}_{2}$ every 30 seconds.

To obtain further insight into the processes occurring in the short time frame, the pulses must be analyzed in more detail. Figure 3 shows, as example, the absorbance at selected wavenumbers monitored by rapid-scan and the NOx removed in the experiment performed with $\mathrm{CuO} / \mathrm{Ce}_{0.8} \mathrm{Zr}_{0.2} \mathrm{O}_{2}$ for one pulse of $\mathrm{CO}$ (Figure 3a) and one pulse of $\mathrm{H}_{2}$ (Figure $3 \mathrm{~b}$ ). The reductant pulses were fed every $30 \mathrm{~s}$, and the dashed vertical lines indicate when a reductant micro-pulse was admitted. The removal of NOx follows the same pattern as the band due to nitrates at $1550 \mathrm{~cm}^{-1}$. As expected, the greater the extent of NOx removal (ie longer lean period) the greater the absorbance due to nitrates. The nitrate band intensity decreases after the pulse of reductant because these species are removed from the catalyst. As mentioned, $\mathrm{H}_{2}$ regeneration is more efficient than $\mathrm{CO}$ regeneration, as deduced from the greater rate at which band intensity at $1550 \mathrm{~cm}^{-1}$ is reduced after the reductant pulse, and from the higher NOx removal levels achieved with $\mathrm{H}_{2}$ pulses compared to CO. 

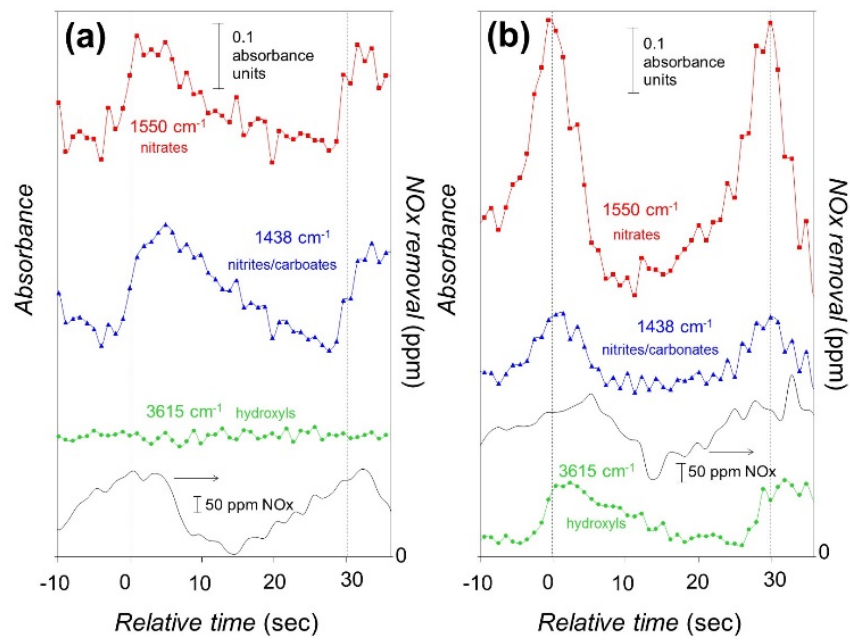

Figure 3. Detail of one pulse monitored by rapid-scan operando DRIFTS-MS in experiments performed with $\mathrm{CuO} / \mathrm{Ce}_{0.8} \mathrm{Zr}_{0.2} \mathrm{O}_{2}$ in a $50 \mathrm{ml} / \mathrm{min}$ flow of $850 \mathrm{ppm}$ $\mathrm{NO}+5 \% \mathrm{O}_{2}+\mathrm{N}_{2}$ (balance) and $100 \mu \mathrm{L}$ pulses of (a) $\mathrm{CO}$ or (b) $\mathrm{H}_{2}$ every 30 seconds.

The pattern of the hydroxyls absorbance during pulses of $\mathrm{H}_{2}$ (Figure $3 b$ ) is the same as those of nitrates and NOx removal. The $\mathrm{H}_{2}$ pulse cleans the catalyst surface, reducing nitrates and nitrites and also releasing hydroxyls as $\mathrm{H}_{2} \mathrm{O}$. Once the surface is clean, $\mathrm{NOx}$ chemisorption begins again and also $\mathrm{H}_{2} \mathrm{O}$ molecules are chemisorbed restoring the population of hydroxyls. This observation cannot be deduced without rapid-scan monitoring. For instance, it is known that hydroxyls are suitable chemisorption sites for NOx, ${ }^{[13]}$ but this is not occurring on the experiments in Figure $3 \mathrm{~b}$. If this were the case and NOx were chemisorbed on hydroxyls, the shape of the nitrites and nitrates profiles would be opposed to those of the hydroxyls, that is, the formation of nitrites and nitrates should lead to the depletion of hydroxyls, and this is not occurring. Therefore, it is possible to rule out that NOx chemisorption on hydroxyls plays an important role, and this conclusion can be only achieved using rapid-scan.

Figure 3 profiles are also useful in identifying the species responsible for the band at $1438 \mathrm{~cm}^{-1}$, which could be assigned to either nitrites and/or to carbonates. Carbonate bands cannot grow during $\mathrm{H}_{2}$ pulses (Figure 3b) due to the absence of carbon source, and in this case the $1438 \mathrm{~cm}^{-1}$ band must be assigned to nitrites. On the other hand, carbonates may be formed after $\mathrm{CO}$ oxidation, hence contributing to the absorbance at $1438 \mathrm{~cm}^{-1}$ together with nitrites (Figure $3 b$ ). This would explain why the absorbance at $1438 \mathrm{~cm}^{-1}$ changes with time to a greater extent in Figure $3 a$ (CO pulses) than in Figure $3 b\left(\mathrm{H}_{2}\right.$ pulses). The competition between carbonates and nitrogen oxides for the chemisorption sites of the catalyst would be an additional argument to explain the less effective regeneration achieved by $\mathrm{CO}$ compared to $\mathrm{H}_{2}$.

In summary, it has been demonstrated that the new concept introduced in this paper, referred to as rapid-scan operando, is a highly powerful tool in the study of reaction mechanisms of heterogeneous catalysis, because it combines rapid-scan for IR monitoring in the milliseconds time frame and operando methodology. As a proof of concept, the NOx-CO and $\mathrm{NOx}-\mathrm{H}_{2}$ reactions have been studied as model catalyzed reactions with practical interest for the removal of NOx in Diesel exhausts. Rapid-scan operando experiments have provided further insight into the reaction mechanisms, and more importantly, have allowed us to elucidate, for the first time, the different role of hydroxyls depending on the reductant used $\left(\mathrm{CO}\right.$ or $\left.\mathrm{H}_{2}\right)$. Moreover, this procedure tool has been used to distinguish the behavior of carbonates and nitrites under reaction conditions, which cannot be achieved by conventional IR approaches as they fail to distinguish the two due to overlapping. Overall, this work provides a remarkable contribution towards the implementation of rapidscan operando methodology as a powerful tool to gain further insights in the mechanism of many other heterogeneous catalysis reactions.

\section{Experimental Section}

Rapid-scan operando DRIFTS experiments were performed using a Shimadzu (IR Tracer-100) Spectrometer with a Harrick reaction cell coupled to an EcoSys-P mass spectrometer. The model $\mathrm{CuO} / \mathrm{CeO}_{2}$ and $\mathrm{CuO} / \mathrm{Ce}_{0.8} \mathrm{Zr}_{0.2} \mathrm{O}_{2}$ catalysts were prepared by wet impregnation of copper nitrate on $\mathrm{CeO}_{2}$ and $\mathrm{Ce}_{0.8} \mathrm{Zr}_{0.2} \mathrm{O}_{2}$ to obtain 5 wt.\% $\mathrm{Cu}$ loading after calcination at $500^{\circ} \mathrm{C}$. For $\mathrm{CeO}_{2}$ and $\mathrm{Ce}_{0.8} \mathrm{Zr}_{0.2} \mathrm{O}_{2}$ preparation, the nitrate precursors were dissolved in the minimum volume of water and the solution was introduced into a furnace previously heated at $200^{\circ} \mathrm{C}$, and after $1 \mathrm{~h}$, the temperature was raised to $500^{\circ} \mathrm{C}$. Detailed catalysts characterization is included in the supplementary material.

\section{Acknowledgements}

Financial support of Generalitat Valenciana (Project PROMETEOII/2014/010 and grant BEST/2014/250), Spanish Ministry of Economy and Competitiveness (Projects CTQ201230703 and MAT2014-61992-EXP, and grant PRX14/00249), and EU (FEDER funding).

Keywords: Infrared spectroscopy - Reaction mechanism • DRIFTS • Operando • Rapid-scan

[1] A. L. Smith. Applied infrared spectroscopy: Fundamentals, techniques and analytical problem-solving. Wiley. New York, 1979.

[2] J. W. Cooley, J. W. Tukey. Mathematics of Computation. 1965, 19, 297 301.

[3] A. Urakawa, N. Maeda, A. Baiker. Angew. Chem. Int. Ed. 2008, 47, 9256 9259

[4] a) G. Liu, P.-X. Gao. Catal. Sci. Technol., 2011, 1, 552-568; b) G. Whiteman, H. Hoster. Nature. 2015, 527, 38; c) J.P. Breen, C. Rioche R. Burch, C. Hardacre, F.C. Meunier, Appl. Catal. B 2007, 72, 178-186 d) J.P. Breen, R. Burch, C. Fontaine-Gautrelet, C. Hardacre, C. Rioche Appl. Catal. B 2008, 81 150-159.

[5] a) J. Dupré, P. Bazin, O. Marie, M. Daturi, X. Jeandel, F. Meunier. Appl Catal. B 2014, 160-161, 335-343; b) I.S. Pieta, M. García-Diéguez, C Herrera, M.A. Larrubia, L.J. Alemany. J. Catal. 2010, 270, 256-267; c) N. Maeda, A. Urakawa, A. Baiker. J. Phys. Chem. C 2009, 113, 16724 16735.

[6] N. Takahashi, H. Shinjoh, T. lijima, T. Suzuki, K. Yamazaki, K. Yokota H. Suzuki, N. Miyoshi, S. Matsumoto, T. Tanizawa, T. Tanaka, S Tateishi, K. Kasahara, Catal. Today 1996, 27, 63-69.

[7] N. Takahashi, K. Yamazaki, H. Sobukawa, H. Shinjoh. Appli. Catal. B 2007, 70, 198-204.

[8] D. Gamarra, A. Martínez-Arias. J. Catal. 2009, 263, 189-195.

[9] K.I. Hadjiivanov. Catal. Rev.Sci. Eng., 2000, 42, 71-144.

[10] a) W.S. Epling, L.E. Campbell, A. Yezerets, N.W. Currier, J.E. Parks II, Catal. Rev. Sci. Eng. 2004, 46, 163-245; b) C. H. Kim, G. Qi, K. Dahlberg W. Li. Science, 2010, 327, 1624-1627. 
[11] D. James, E. Fourré, M. Ishii, M. Bowker, Appl. Catal. B 2003, 45 147159.

[12] a) Z. Liu, J. A. Anderson. J. Catal., 2004, 224, 18-27; b) T. Szailer, J. H. Kwak, D. H. Kim, J. C. Hanson, C. H.F. Peden, J. Szanyi. J. Catal. 2006, 239, 51-64.
[13] I. Atribak, B. Azambre, A. Bueno López, A. García-García. Appl. Catal. B 2009, 92, 126-137 
Table of Contents

\section{COMMUNICATION}

Rapid-scan consists of recording IR spectra in the milliseconds time frame, and combined with operando methodology, is a highly powerful method to study reaction mechanisms of heterogeneous catalysis.

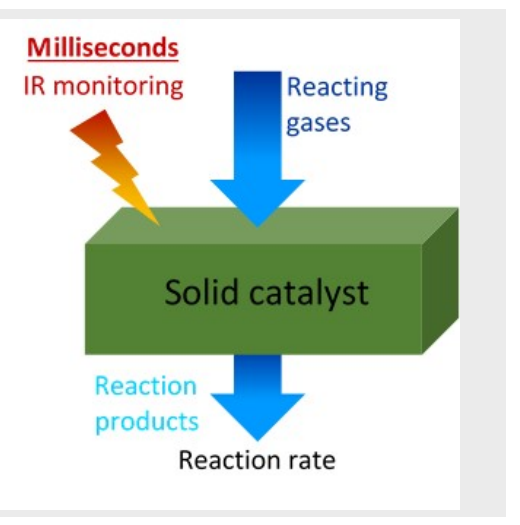

Arantxa Davó-Quiñonero, Agustín Bueno-López*, Dolores LozanoCastelló, Alan J. McCue, James A. Anderson.

Page No. - Page No.

Rapid-scan operando infrared spectroscopy 